JOURNAL OF ENGINEERING SCIENCES

Volume 7, Issue 1 (2020)

Lukashov, V. K., Kostiuchenko, Y. V., Timofeev, S. V., Ochowiak, M. (2020). An experimental study of heat and mass transfer in a falling liquid film evaporation into a cross flow of a neutral gas. Journal of Engineering Sciences, Vol. 7(1), pp. F30-F38, doi: 10.21272/jes.2020.7(1).f3.

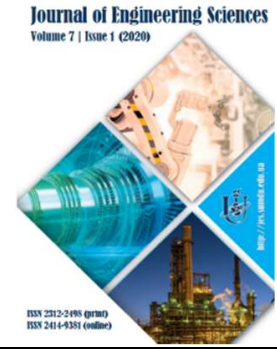

\title{
An Experimental Study of Heat and Mass Transfer in a Falling Liquid Film Evaporation into a Crossflow of Neutral Gas
}

Lukashov V. K. ${ }^{1}$, Kostiuchenko Y. V. ${ }^{1}$, Timofeev S. V. ${ }^{1}$, Ochowiak M. ${ }^{20000-0003-1543-9967]}$

\author{
${ }^{1}$ Shostka Institute of Sumy State University, 1, Haharina St., 41100 Shostka, Ukraine; \\ ${ }^{2}$ Poznan University of Technology, 5, M. Sklodowskiej-Kurie Sq., 60-965 Poznan, Poland
}

Article info:

Paper received:

The final version of the paper received:

Paper accepted online:
*Corresponding email:

February 17, 2020

May 28, 2020

June 11, 2020

\author{
khtms@ishostka.sumdu.edu.ua
}

\begin{abstract}
The work is devoted to the study of heat and mass transfer in a liquid film flowing down on a heated surface under conditions of evaporation into a crossflow of a gas neutral with respect to the liquid. The work aimed to experimentally determine the average heat transfer coefficients from a heated surface to the film, heat transfer and mass transfer from the film to the gas flow and to establish their dependence on the input parameters of the heat and mass transfer process. To achieve this goal, an experimental setup was created, and a research technique was developed based on the proposed mathematical model of the heat and mass transfer process. The results of the study showed that the dependences of the average heat and mass transfer coefficients on the initial liquid flow rate are extreme with the minimum values of these coefficients at the liquid flow rate, which corresponds to the critical value of the Reynolds criterion $\operatorname{Re}_{1 \mathrm{cr}} \approx 500$, which indicates a transition from the laminar falling films to turbulent mode under the considered conditions. The dependences of the heat and mass transfer coefficients on other process parameters for both modes of film falling are established. A generalization of the experimental data made it possible to obtain empirical equations for calculating these coefficients.
\end{abstract}

Keywords: heat and mass transfer, cross flow, film apparatus, heat and mass return coefficient, neutral gas.

\section{Introduction}

Apparatus with gravitational film falling of a liquid are widely used in industry for carrying out various technological processes. In many cases, these processes are accompanied by the evaporation of a liquid with a free surface of the film (concentration of solutions, evaporative cooling). The presence of a neutral (inert) gas flow with respect to the liquid over the film has a significant effect on heat and mass transfer in such processes, allows them to be carried out at a lower temperature, and to ensure high efficiency of the apparatus $[1,2]$.

\section{Literature Review}

The processes of heat and mass transfer in film apparatus are the subject of a large number of works published over many decades, starting from the first publication (V. Nusselt, 1916). Despite this, this problem is attracting researchers at the present time, which is associated with the development of technologies in which film apparatus are used. Many recent publications are devoted to the mathematical modeling of these processes [3-6]. A number of works present the results of experimental studies of the processes of heat and mass transfer in a liquid film that evaporates into the gas phase under various conditions of flow. Experimental studies, as a rule, consist in determining the heat and mass transfer coefficients, which are necessary for the closure of theoretical models. For example, in [7], the results of an experimental study of the heat transfer of a falling film of binary mixtures of freons with a surface of complex geometry with a local heater are reported. It is shown that in the evaporation mode, the heat transfer coefficients are determined by the liquid flow rate and weakly depend on the heat flux. The authors of $[8,9]$ presented experimental data on the cooling of a falling film of water at various flow regimes and calculated the values of the heat transfer coefficients from a liquid to ambient air. In [10], heat and mass transfer were studied during the evaporative cooling of a liquid film falling down a channel under countercurrent gas motion. The results of the study showed the nonlinear nature of the change in 
the coefficients of heat and mass transfer along the length of the channel. The heat transfer, during evaporation of an ascending and descending liquid film into a moving air stream as applied to the desalination of seawater, was studied in [11]. The obtained experimental data are generalized by the criterion equation, which allows us to calculate the heat transfer coefficient.

However, in these works, as in previously published ones, the heat and mass transfer coefficients are determined under the conditions of direct-flow or counter-current interaction of the film with the gas flow. At the same time, for increasing the efficiency of technological processes, the cross interaction of flows is of interest [2, 12]. Known studies also do not consider the structure of the heat flux from the surface of the film into the gas phase and the features of evaporation in the presence of neutral gas. In this regard, this work aims to experimentally determine the heat and mass transfer coefficients during evaporation of a liquid film falling down a heated vertical surface into a cross-flow of neutral gas and establish their dependence on the input parameters of the heat and mass transfer process.

\section{Research Methodology}

\subsection{Description of the experimental setup and experiments}

The study was carried out in an experimental setup (Fig. 1), which is a model of an element of a film apparatus [2].

The main unit of the installation is a rectangular tank 1 , made of sheet steel, with a wall 2 , the outer (working) surface of which serves to fall the liquid film. The dimensions of this surface are: height $H=800 \mathrm{~mm}$, width $b=100 \mathrm{~mm}$. A liquid distributor 3 is installed on top of the tank 1 for its uniform distribution over the width of the surface. On one of the long sides of the tank, a gas distributor 4 is fixed, having a slot $3 \mathrm{~mm}$ wide over the entire height, directed to the working surface of the wall 2. The tank 1 is filled with a high-temperature coolant (glycerin), which is in contact with the inner surface of the wall 2. The coolant is circulated using a liquid thermostat 5 . To evenly heat the wall 2 and ensure the desired temperature, an additional electric heater 6 is placed inside the tank 1 . At a distance of $18 \mathrm{~mm}$ from the working surface of the wall 2 , the enclosing wall 7 is located, which is made of a transparent material, which allows visual observations of the fluid flow. The gas distributor 4 is connected to an air duct, on which an air electric heater 8 , an airflow meter 9 , and control valves 10 are installed. The duct is connected to the blower 11 . The setup has a supply system of liquid, which consists of a supply tank 12, a pressure tank 13 with an electric heater, a collector 14 , a circulation pump 15, a control valve 16 , shut-off valves $17,18,19$, graduated cylinders 20 and 21 . It is equipped with laboratory thermometers of the TL-50 brand (measurement scale 0-250, calibration $1{ }^{\circ} \mathrm{C}$ ) for temperature measurements of heat coolant in thermostat 5 (T1) and in tank 1 located along with its height (T2, T3, T4); air in the gas distribution device
(T5, T6) and located between the walls 2 and 7 located at its height (T7, T8, T9); liquid in the liquid distributor (T10) and flowing down with the working surface (T11).

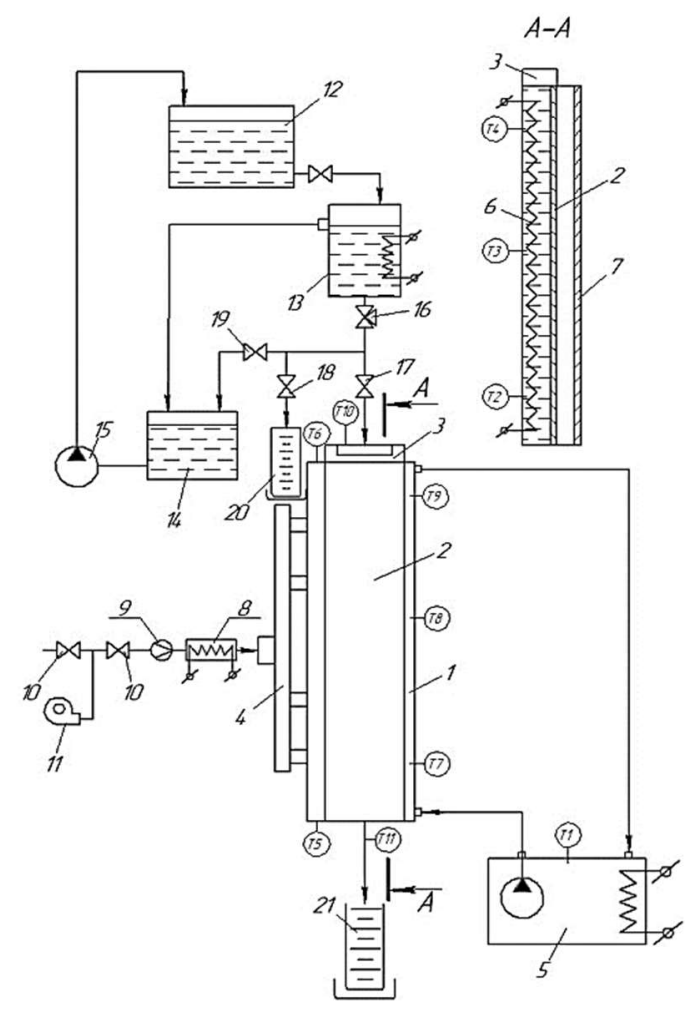

Figure 1 - Scheme of the experimental setup

1 - tank with a heat coolant; 2 - wall with a working surface;

3 - liquid distributor; 4 - gas distributor; 5 - thermostat;

6 - electric heater; 7 - the enclosing wall; 8 - electric air

heater; 9 - flowmeter; 10 - control valve for air; 11 - blower;

12 - supply tank; 13 - pressure tank; 14 - collection;

15 - circulation pump; 16 - control valve for liquid;

17, 18, 19 - shut-off valves; 20, 21 - graduated cylinders.

The experiments were carried out in the following sequence. From the supply tank 12, the liquid was supplied to the pressure tank 13 with the valves 17,18 closed. After filling it, the valve 18 was opened, and the control valve 16 set specific liquid flow rate, which was measured using a graduated cylinder 20 with the valve 18 open and the valve 19 closed. Upon completion of the measurement of liquid flow, the valve 18 was closed and the valve 17 was opened, as a result of which the liquid entered the distributor 3 , which forms a liquid film of a given width on the working surface of the wall 2 . The flow rate of liquid falling from this surface was measured by a graduated cylinder 21 . In this study, water was used as a liquid.

Then we switched on the thermostat 5, electric heater 6 , electric heater of a tank 13, and set the desired temperature of the coolant, as well as the water entering the distributor 3. Next, the blower 11, the electric heater 8 were turned on, and with the help of the valves 10 , the flow rate of air entering the gas distributor 4 was set by the flow meter 9 , followed by recalculation on the air rate in the space between walls 2 and 7. Additionally, airspeed 
was also monitored by periodic measurements using a portable anemometer at the outlet of this space.

The input parameters in this study were: flow rate $L_{0}$ $(\mathrm{kg} / \mathrm{s})$ and temperature $t_{l 0}\left({ }^{\circ} \mathrm{C}\right)$ of water in the distributor 3 , taken as the characteristics of the initial cross section of the film formed by the distributor 3; rate $v(\mathrm{~m} / \mathrm{s})$ and temperature $t_{g 0}\left({ }^{\circ} \mathrm{C}\right)$ of air entering the space between walls 2 and 7 ; coolant temperature $t_{c}\left({ }^{\circ} \mathrm{C}\right)$ in tank 1. Output parameters: flow rate $L(\mathrm{~kg} / \mathrm{s})$ and temperature $t_{f}\left({ }^{\circ} \mathrm{C}\right)$ of water falling from the working surface of the wall 2 , taken as the characteristics of the final cross section of the film; air temperature $t_{g}\left({ }^{\circ} \mathrm{C}\right)$ at the exit from the space between walls 2 and 7 . Using these parameters, taking into account the environmental parameters: temperature $t_{e n}\left({ }^{\circ} \mathrm{C}\right)$, relative humidity $\varphi(\%)$ and atmospheric pressure $B(\mathrm{~Pa})$, we calculated the average coefficients by the height of the surface: heat transfer coefficient $K_{f}\left(\frac{J}{m^{2} \cdot s \cdot d e g}\right)$ from the coolant to the liquid film; heat return coefficient $\alpha_{c}\left(\frac{J}{m^{2} \cdot s \cdot d e g}\right)$ and mass return coefficient $\beta\left(\frac{\mathrm{kg}}{\mathrm{m}^{2} \cdot \mathrm{s} \cdot \mathrm{Pa}}\right)$ from the film to the gas flow.

In the course of the experiments, it was found that the width of the film flowing down the heated surface decreases with increasing distance from its initial section, while the flowing down along the unheated surface, it remains constant. This phenomenon can be explained by the thermocapillary effect arising as a result of intense evaporation of the liquid in the region of the "liquid vapor - wall" contact line, which leads to a change in the curvature of the interphase surface $[13,14]$. It requires a separate study, therefore, in this work, reduced film widths, which in many cases reached $50 \%$, were taken into account for each experiment by measuring the film width by the height of the working surface, followed by recalculation through the film surface area to its average width $\mathrm{b}_{f}(\mathrm{~m})$.

\subsection{Development of a mathematical model for calculating heat and mass return coefficients}

In developing this mathematical model, the following assumptions were made:

- the characteristics of the film are considered as a constant along its width;

- friction between the surface of the film and the gas flow is not considered;

- heat and mass transfer occurs under steady-state hydrodynamic and thermal conditions;

- the density $\rho_{l}$ and specific heat $c_{l}$ of the liquid are taken such that they are independent from the temperature of the liquid in the considered range of its change.

Based on these assumptions for a work surface of height $H$ and width $b$, we write the heat balance equations:

- for a liquid film:

$$
Q_{h}+Q_{f 0}-Q_{f}-Q_{v} \pm Q_{t}=0
$$

- for the gas phase above the film:

$$
Q_{g 0}+Q_{v} \pm Q_{t} \pm Q_{s} \pm Q_{g}-Q_{l}=0,
$$

where the terms of equation (1) and (2) express heat flows $(\mathrm{J} / \mathrm{s})$ :

$Q_{h}=K_{f}\left(t_{c}-t_{\Pi f}\right) b_{f} H-$ supplied to the film through the wall from the heat coolant;

$Q_{f 0}=\rho_{l} c_{l} u_{f 0} t_{f 0} b_{f} \delta_{0}-$ incoming with the liquid entering the surface;

$Q_{f}=\rho_{l} c_{l} u_{f} t_{f} b_{f} \delta$ - escaping with liquid draining from the surface;

$Q_{v}=w r b_{f} H-$ transported to the gas phase with vapor;

$Q_{t}=\alpha_{c}\left(t_{f}-t_{g}\right) b_{f} H-$ transmitted during interphase heat exchange (the "+" sign is from gas, the "-" sign is from the film);

$Q_{g 0}=\rho_{g 0} c_{g 0} t_{g 0} v H \Delta-$ entering the space above the film with a gas flow;

$Q_{s}=\alpha_{s}\left(t_{w 0}-t_{g}\right)\left(b-b_{f}\right) H-$ transmitted to the gas phase during heat exchange between the gas flow and the wall surface, which is not covered with liquid (the "+" sign is from the surface, the "-." sign is from gas);

$Q_{g}=\rho_{g} c_{g} t_{g} v H \Delta-$ coming out of the space above the film with a gas flow;

$Q_{l}=K_{e n}\left(t_{g}-t_{e n}\right) b H-$ lost in the environment through the enclosing wall.

Physical quantities included in the expressions for the specified flows: $u_{f 0}, u_{f}-$ the speed of the film in its initial and final sections, $\mathrm{m} / \mathrm{s} ; \delta_{0}, \delta-$ film thickness in its initial and final sections, $\mathrm{m} ; w$ - liquid evaporation rate from the film surface, $\frac{\mathrm{kg}}{\mathrm{m}^{2} \cdot \mathrm{s}} ; r-$ specific heat of vaporization, $\mathrm{J} / \mathrm{kg} ; \rho_{g 0}, \rho_{g}$ - the density of wet gas at the entrance to the space between the walls and the exit from it, $\frac{\mathrm{kg}}{\mathrm{m}^{3}} ; c_{g 0}, c_{g}-$ specific heat at the entrance and exit from the space between the walls, $\frac{\mathrm{J}}{\mathrm{kg} \cdot \mathrm{deg}} ; \Delta-$ the distance between the working surface and the enclosing wall, m; $\alpha_{s}-$ heat return coefficient between the surface of uncoated by the film and the gas flow, $\frac{J}{m^{2} \cdot s \cdot d e g} ; t_{w 0}-$ the wall surface temperature which is not yet heated by the film; $K_{e n}$ - the heat return coefficient from the gas flow to the environment through the enclosing wall, $\frac{\mathrm{J}}{\mathrm{m}^{2} \cdot \mathrm{s} \cdot \mathrm{deg}}$

The mathematical model, along with equations (1) and (2), includes the equations obtained in [15]: the motion of a liquid in a film; film continuity; mass return from the free surface of the film; a material balance of the gas phase in the evaporated liquid; the relative content of the vaporized substance in the gas phase; Dalton's law.

From equation (1) as a result of the substitution of the expressions of its members and the subsequent transformation, we obtain the formula:

$$
K_{f}=\frac{\rho_{l} c_{l}\left(u_{f} t_{f} \delta-u_{f 0} t_{f 0} \delta_{0}\right)}{\left(t_{c}-t_{f}\right) H}+\frac{w r}{t_{c}-t_{f}}-\alpha_{c} \frac{t_{f}-t_{g}}{t_{c}-t_{f}} .
$$

This formula makes it possible to calculate the average heat transfer coefficient from the heated coolant to the 
liquid film from experimentally determined input and output parameters of the heat and mass transfer process. The necessary values of the motion velocity and film thickness in its initial and final cross sections were calculated from the dependencies obtained in [15]. In order to summarize the experimental data, the values of the heat transfer coefficient $K_{f}$ were calculated on the heat transfer coefficient from the surface to the film $\alpha_{f}$ according to the formula obtained from the known relations connecting the heat transfer coefficient with heat return coefficients

$$
\alpha_{f}=\frac{K_{f} \alpha_{c} \lambda_{w}}{\alpha_{c} \lambda_{w}-K_{f}\left(\lambda_{w}+\Delta_{w} \alpha_{c}\right)},
$$

where $\alpha_{c}$ is the heat return coefficient from the coolant with the inner surface of the wall in contact with it, $\frac{J}{m^{2} \cdot s \cdot d e g} ; \lambda_{w}-$ thermal conductivity of the wall, $\frac{J}{m \cdot s \cdot d e g}$; $\Delta_{w}$ - wall thickness, $\mathrm{m}$.

From equation (2), a formula was obtained for calculating the heat return coefficient from the film surface to the gas flow

$$
\begin{gathered}
\alpha_{c}=\frac{\left(c_{g} \rho_{g} t_{g}-c_{g 0} \rho_{g 0} t_{g 0}\right) v \Delta}{\left(t_{f}-t_{g}\right) b_{f}}-\frac{w r}{t_{f}-t_{g}}-\alpha_{s} \frac{\left(t_{w 0}-t_{g}\right)\left(b-b_{f}\right)}{\left(t_{f}-t_{g}\right) b_{f}}+ \\
+K_{e n} \frac{\left(t_{g}-t_{e n}\right) b}{\left(t_{f}-t_{g}\right) b_{f}}
\end{gathered}
$$

In this case, the wall surface temperature $t_{w 0}$ was taken to be equal to the coolant temperature, and the surface temperature $t_{w}$, according to which the film flows, necessary for further calculations, was determined by the formula obtained from the heat return equation

$$
t_{w}=t_{f}+\frac{K_{f}\left(t_{c}-t_{f}\right)}{\alpha_{f}} .
$$

The heat transfer coefficient $K_{e n}$, which is part of the formula (4), was determined from the known dependences expressing the heat return from the gas flow to the enclosing wall and from this wall to the environment, taking into account the thickness and thermal conductivity of the enclosing wall. Densities and specific heat capacities of moist air at the inlet and outlet of the space between the walls included in formula (4) were determined using the dependencies

$$
\begin{gathered}
\rho_{g 0}=\frac{\left(B-P_{v 0}\right)\left(1-d_{g 0}\right)}{287\left(273+t_{g 0}\right)} ; \rho_{\Gamma}=\frac{\left(B-P_{v}\right)\left(1-d_{g}\right)}{287\left(273+t_{g}\right)} ; \\
c_{g 0}=1 \cdot 10^{3}+1.97 \cdot 10^{3} d_{g 0} ; \\
c_{g}=1 \cdot 10^{3}+1.97 \cdot 10^{3} d_{g} ;
\end{gathered}
$$

where $P_{v 0}, P_{v}$ - partial vapor pressure of the vaporized substance in the gas flow at the inlet and outlet of the space between the walls, $\mathrm{Pa} ; d_{g 0}, d_{g}$ - the moisture content of gas at the inlet and outlet of the space between the walls, $\mathrm{kg}$ moisture/kg dry air.

The average surface height mass return coefficient for each particular experiment was determined based on the mass return equation [15]:

$$
\beta=\frac{w}{P_{a b}-P_{u n}},
$$

where $P_{a b}$ - saturated vapor pressure of the vaporized substance at a gas temperature above the film, $\mathrm{Pa} ; P_{u n}-$ the partial pressure of steam in the vapor-gas mixture under the film, $\mathrm{Pa}$.

The rate of evaporation of the liquid was calculated as

$$
w=\frac{L_{0}-L}{b_{\text {пл }} H}
$$

Using the measured environmental parameters, the moisture content of the ambient air $d_{e n}$ ( $\mathrm{kg}$ moisture $/ \mathrm{kg}$ dry air) taken by the blower was determined, and the mass flow rate of absolutely dry air $G_{g}(\mathrm{~kg} / \mathrm{s})$ was calculated using the dependencies given in [15]. Given $d_{g 0}=d_{e n}$, where $d_{g 0}$ is the moisture content of the air supplied to the space between the walls (after the electric heater), the moisture content of the air under the film was calculated

$$
d_{g}=\frac{L_{0}-L}{G_{g}}+d_{g 0}
$$

and, accordingly, the partial pressure of steam in this air using the formula obtained in [15]

$$
P_{u n}=\frac{d_{g} m_{g} B}{m_{w}+d_{g} m_{g}},
$$

where $m_{g}, m_{w}$ is the mass of one kilomole, respectively, of absolutely dry and wet steam, $\mathrm{kg} / \mathrm{mol}$.

\section{Results and Discussion}

The results of the study were presented in the form of dependences of the average heat and mass return coefficients on the input parameters of the heat and mass transfer process.

An analysis of the influence of the initial flow rate (irrigation density) of the liquid $\mathrm{L}_{0}$ on the indicated coefficients showed that the character of the dependences of all the coefficients on this parameter is approximately the same (Fig. 2).

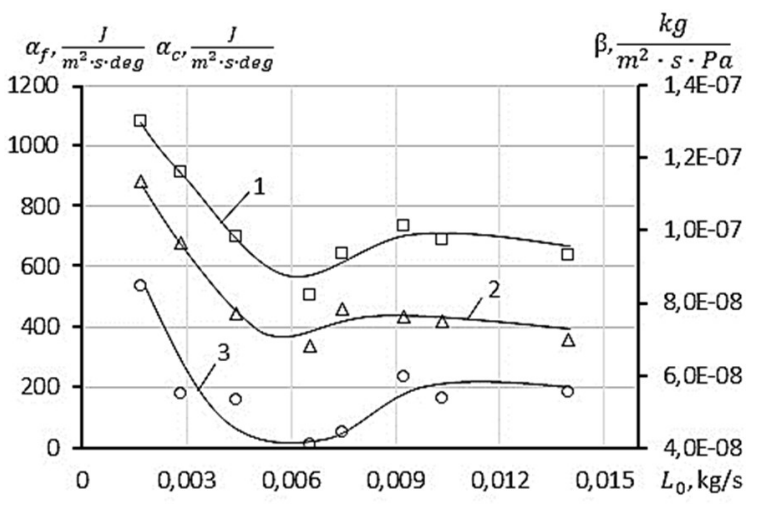

Figure 2 - Dependences of the coefficients of heat and mass return on the initial consumption of liquid: $1-\alpha_{f}=f\left(L_{0}\right) ; 2-\alpha_{c}=f\left(L_{0}\right) ; 3-\beta=f\left(L_{0}\right)$. 
With an increase in liquid flow rate, the heat and mass return coefficients first decrease, reaching a minimum value, and then begin to increase. Such an extreme character of these dependencies is confirmed by published data as applied to the heat return coefficient from the surface to the film [16]. It is explained by the transition from the laminar mode of film motion to turbulent. In the laminar mode, with an increase in the liquid flow rate, the film thickness increases, which leads to a decrease in the heat return coefficient from the surface to the film, and, as the data are shown in Fig. 2 show, also the heat and mass transfer coefficients from the film to the gas phase. Upon transition to a turbulent regime, the heat and mass transfer intensity increases, but this growth is limited by relatively small values of the indicated coefficients, and with a further increase in the liquid flow rate, a slight decrease is observed (Fig. 2). This can be explained by the fact that, by its nature, the liquid film falling down a vertical surface has an unstable wave character [16]. At high liquid flow rates, ordinary two-dimensional waves that occur on the surface in the laminar mode, in the turbulent mode under conditions of evaporation and cross-gas flow, can transform into threedimensional waves with a large amplitude, when the fluctuations in the thickness and velocity of the film exceed their average values [17]. It can be assumed that such an unstable motion of the film leads to a decrease in the intensity of heat and mass transfer.

Representation of the dependences shown in Figure 2 in the dimensionless variables $N u_{f}, N u_{c}, S h$ and $R e_{l}$, expressing the corresponding heat and mass return coefficients, as well as the liquid flow rate, allows us to linearize these dependencies in logarithmic coordinates (Fig. 3), where $N u_{f}=\frac{\alpha_{f}}{\lambda_{l}}\left(\frac{v_{l}^{2}}{g}\right)^{1 / 3} ; N u_{c}=\frac{\alpha_{c}}{\lambda_{g}}\left(\frac{v_{g}^{2}}{g}\right)^{1 / 3}$; $S h=\frac{\beta}{D_{g}}\left(\frac{\nu_{g}^{2}}{g}\right)^{1 / 3} ; R e_{l}=\frac{4 D_{0}}{\mu_{l}} ; \lambda_{l}-$ thermal conductivity of the liquid, $\frac{J}{m^{2} \cdot s \cdot d e g} ; v_{l}-$ kinematic coefficient of liquid viscosity $\mathrm{m}^{2} / \mathrm{s} ; g$ - acceleration of gravity, $D_{g}-$ the vapor diffusion coefficient in the gas phase, $\Gamma_{0}=\frac{L_{0}}{b_{f}}-$ initial linear watering mass, $\frac{\mathrm{kg}}{\mathrm{m} \cdot \mathrm{s}} ; \mu_{l}$-dynamic coefficient of fluid viscosity, $\mathrm{Pa} \cdot s$.

The characteristic kink of the straight lines in the graph of linearized dependencies allows us to determine the critical value of the criterion $R e_{l}$, which, as follows from Figure 3, is approximately the same for all these coefficients and is equal to $R e_{l c r} \approx 500$. A further study of the dependence of the heat and mass return coefficients on the input parameters of the heat and mass transfer process was presented separately for the laminar $\left(R e_{l}<R e_{l c r}\right)$ and turbulent $\left(R e_{l}>R e_{l c r}\right)$ modes.

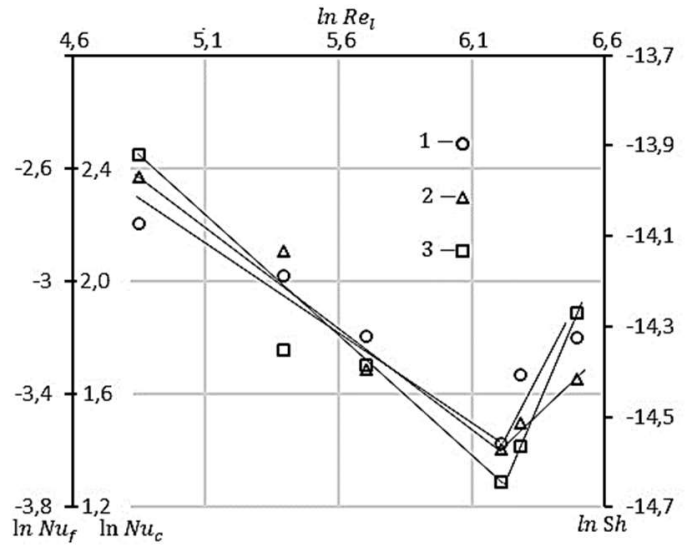

Figure 3 - Dependence of dimensionless heat and mass return coefficients on the Reynolds criterion:

$1-N u_{f}=f\left(R e_{l}\right) ; 2-N u_{c}=f\left(R e_{l}\right) ; 3-S h=f\left(R e_{l}\right)$

The results of these studies showed that the $\alpha_{f}$ coefficients in both modes of film flowing grows linearly with increasing gas velocity, but in the laminar mode, its growth occurs more intensively (Fig. 4 a).

The coefficient $\alpha_{f}$ also increases with an increase in the initial gas temperature (Fig. 4 b). In this case, the influence of film flowing modes also consists in its more intensive growth in the laminar regime than in the turbulent one. The first mode is characterized by a parabolic dependence, while the second is linear. An increase in the coefficient $\alpha_{f}$ in accordance with the parabolic function in the laminar regime is also observed for its dependence on the initial temperature of the liquid, while in the turbulent mode this temperature practically does not affect the coefficient $\alpha_{f}$ (Fig. 4 c).

The dependence of the coefficient $\alpha_{f}$ on the wall surface temperature is more complex in both laminar and turbulent modes (Fig. 4 d). First, with increasing surface temperature, the coefficient $\alpha_{f}$ decreases, then after reaching a temperature approximately corresponding to the boiling point of the liquid $\left(100{ }^{\circ} \mathrm{C}\right)$, it begins to increase. In both modes of film falling, the dependences $\alpha_{f}=f\left(t_{w}\right)$ approach a parabolic function.

As for the heat return coefficient from the film to the gas phase, for all parameters of the heat and mass transfer process, with the exception of the gas velocity, an increase in this coefficient is characteristic for both modes of film falling with increasing them (Fig. 5).

The dependence $\alpha_{c}=f(v)$ is clearly extreme in both laminar and turbulent modes (Fig. 5a). With an increase in the gas velocity, the coefficient $\alpha_{c}$ first decreases, then reaching a minimum value at a gas velocity of $v \approx 1.0$ $\mathrm{m} / \mathrm{s}$, it begins to grow. For both modes of film falling, this dependence corresponds quite well to the parabolic function. 

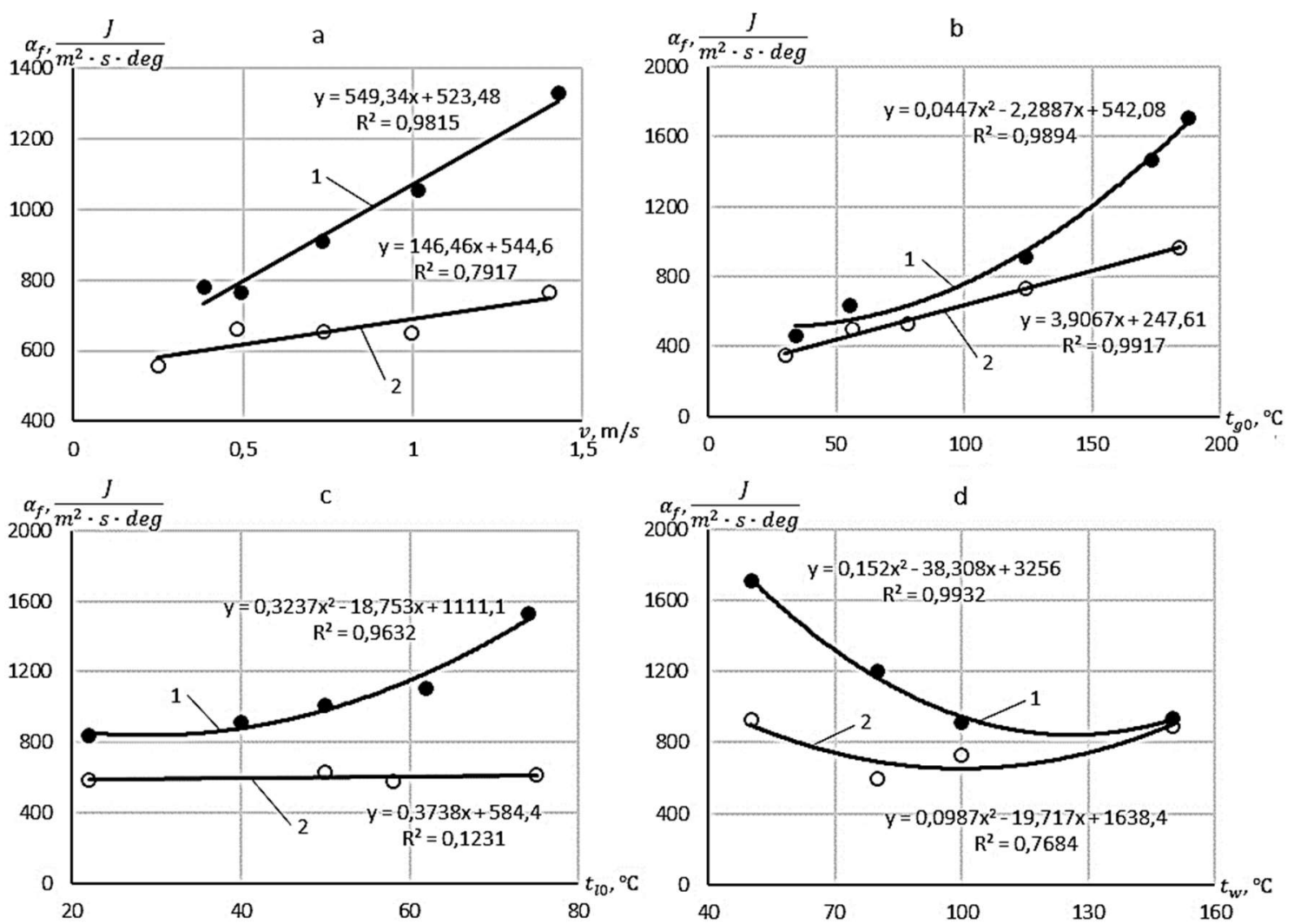

Figure 4 - The dependence of the heat return coefficient from the surface to the film on the parameters of the process of heat and mass transfer: $1-R e_{l}<R e_{l c r} ; 2-R e_{l}>R e_{l c r}$
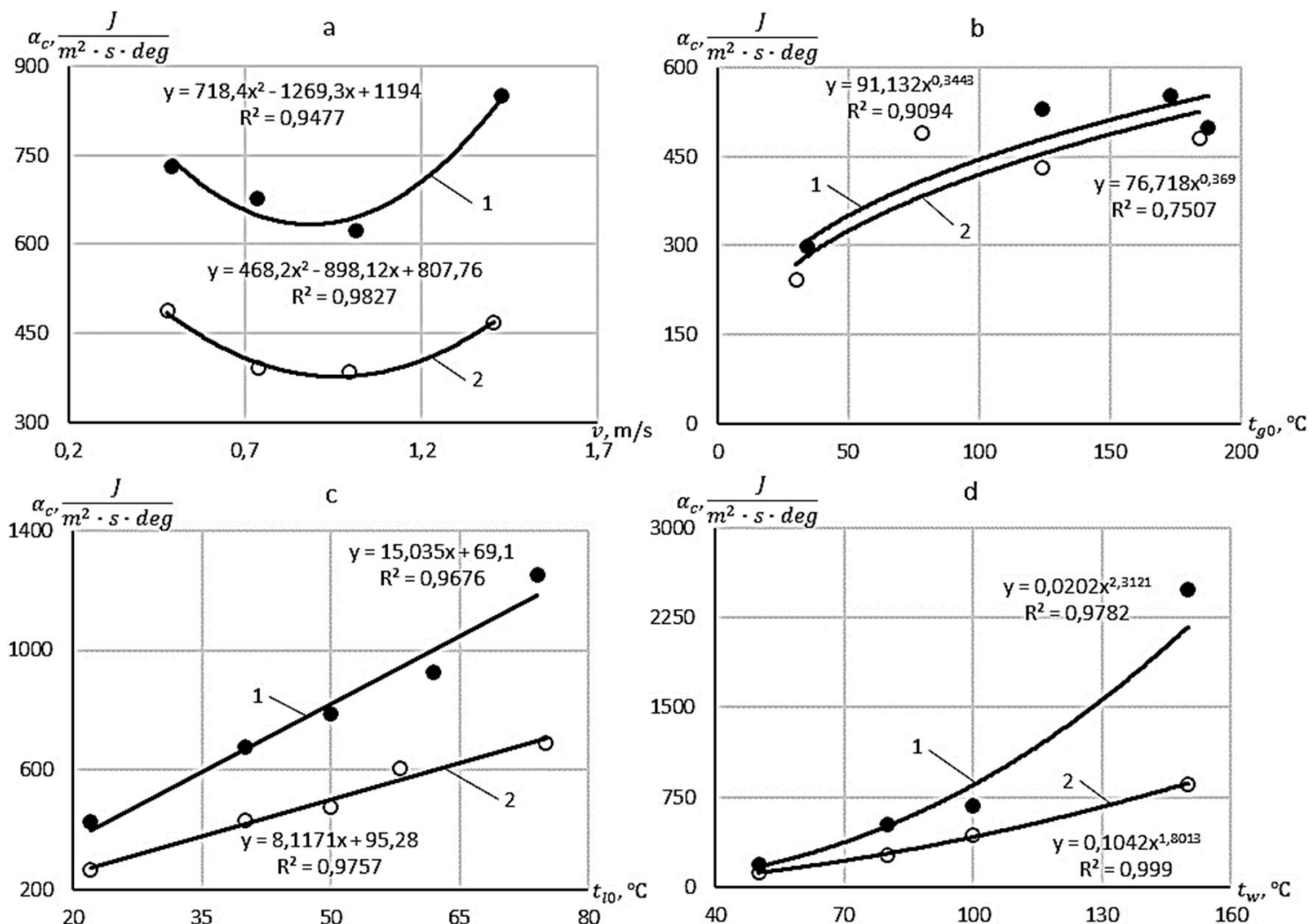

Figure 5 - Dependence of the heat return coefficient on the film in the gas flow on the parameters of the heat and mass transfer process: $1-R e_{l}<R e_{l c r} ; 2-R e_{l}>R e_{l c r}$ 
It can be assumed that this character of the dependence $\alpha_{c}=f(v)$ is associated with a laminar-turbulent transition in the gas phase with an increase in the gas velocity and the manifestation of tangential stresses at the interphase boundary under the conditions of the wave motion of the film.

A specific feature of the influence of other parameters of the heat and mass transfer process on the coefficient $\alpha \mathrm{t}$ is the practical coincidence (within the range of experimental points) of the dependence $\alpha_{c}=f\left(t_{g 0}\right)$ in the laminar and turbulent modes (Fig. 5 b), and also a higher growth rate of the coefficient $\alpha$ in the laminar mode than turbulent with increasing liquid temperature (Fig. 5 c) and surface temperature (Fig. 5 d), and the dependence $\alpha_{c}=f\left(t_{l 0}\right)$ is linear.

The dependences of the mass return coefficient on the liquid film in the gas flow $\beta$ on the gas velocity, in contrast to such dependences of the heat return coefficient, have a different character for the laminar and turbulent regimes (Fig. 6 a).
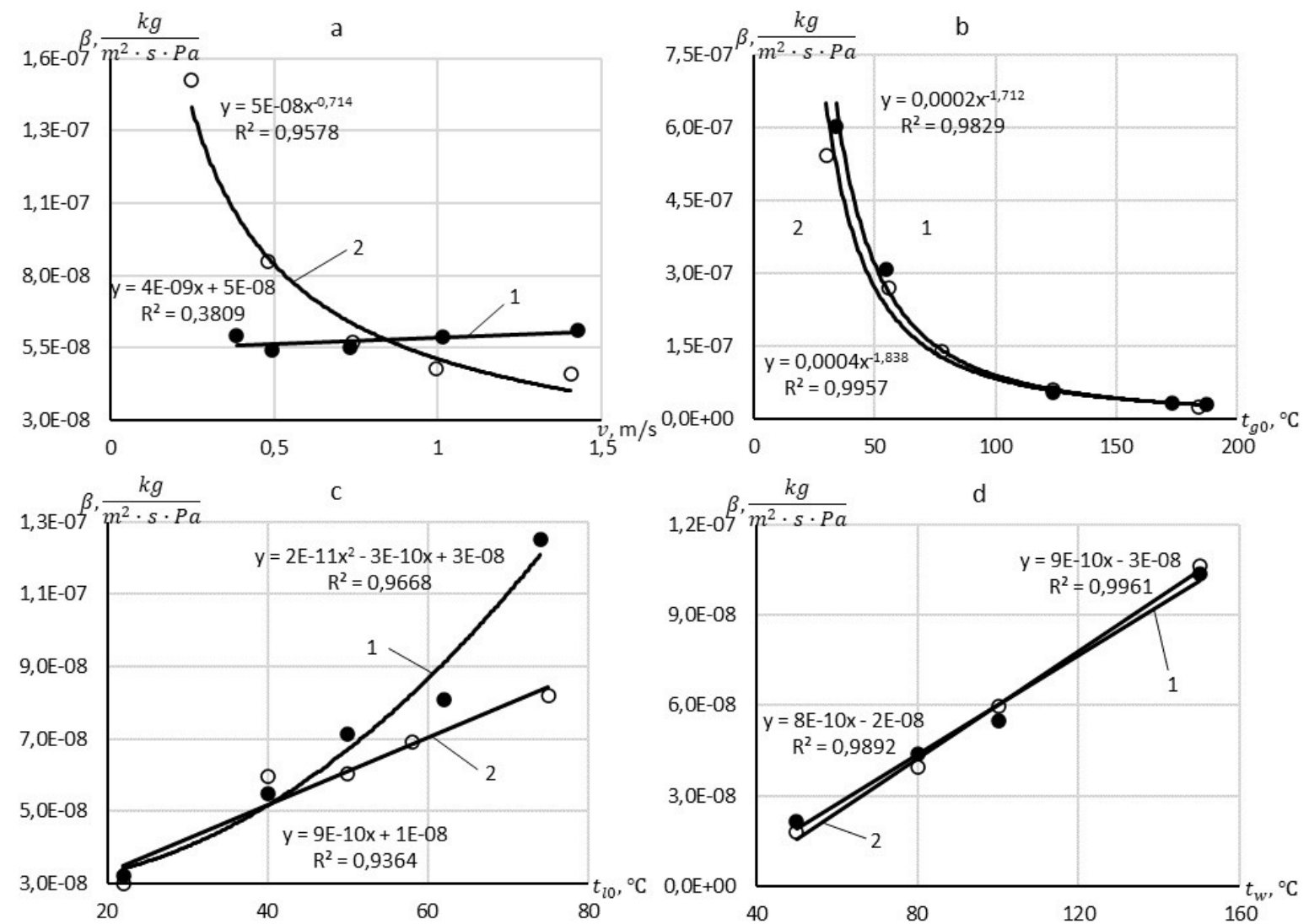

Figure 6 - Dependence of the coefficient of mass return to the gas stream on the parameters of the heat and mass transfer process:

$$
1-R e_{l}<R e_{l c r} ; 2-R e_{l}>R e_{l c r}
$$

For the laminar regime, the coefficient $\beta$ decreases with increasing gas velocity, and the intensity of the decrease is greater in the range of low velocities than in the range of large ones. At low speeds, the values of the coefficient $\beta$ for the laminar regime are smaller than in the turbulent mode, and at high speeds, they are more significant. For the turbulent regime, a slight increase in the coefficient $\beta$ is observed with an increase in the gas velocity practically in accordance with the linear function. With an increase in the initial temperature of the liquid, the coefficient $\beta$ increases in both modes of the film falling: more intensively, in accordance with the parabolic function, in the laminar mode and less intensively, in accordance with the linear function, in the turbulent mode (Fig. 6c). The dependences of the coefficient $\beta$ on the initial gas temperature (Fig. 6b) and surface temperature (Fig. 6d) practically coincide with both regimes. With increasing initial gas temperature, the coefficient $\beta$ decreases, first intensively (to about $100^{\circ} \mathrm{C}$ ), then the decrease occurs less intensively. With increasing surface temperature, the coefficient $\beta$ increases in accordance with a linear function.

Thus, the heat and mass return coefficients depend on almost all of the initial parameters of the heat and mass transfer process, with the exception of the initial liquid temperature, the coefficient $\alpha_{f}$ does not depend on it under turbulent mode (Fig. 4 c). The dependence of the coefficient $\beta$ on the gas velocity in the laminar regime is weakly manifested (Fig. 6 a).

The mathematical processing of experimental data was carried out using the methods of generalized variables, which allowed us to express the dependences of the dimensionless heat and mass return coefficients $N u_{f}$, $N u_{c}, S h$ on the criteria: $R e_{l} ; R e_{g} ; \operatorname{Pr}_{l} ; \operatorname{Pr}_{g} ; S c$, where 
$R e_{g}=\frac{v l_{e q}}{v_{g}}$ is the Reynolds criterion for the gas flow; $\operatorname{Pr}_{l}=\frac{v_{l}}{a_{l}}-$ the Prandtl criterion for a liquid film; $\operatorname{Pr}_{g}=\frac{v_{g}}{a_{g}}-$ the Prandtl criterion for gas flow; Sc $=\frac{g}{g}-$ the Schmidt criterion for gas flow; $l_{e q}=\sqrt{\frac{4 H \Delta}{\pi}}-$ the characteristic size of the gas flow, m; $a_{l}, a_{g}$ - thermal diffusivity for liquid and gas, $\mathrm{m}^{2} / \mathrm{s}$.

Given the significant influence on the surface heat and mass return coefficients, which is not reflected in the indicated criteria, simplices $t_{w} / t_{g 0}$ and $t_{w} / t_{l 0}$ were additionally introduced into these dependencies. It was also considered that the criteria $R e_{l}$ and $\operatorname{Pr}_{l}, R e_{g}$ and $P r_{g}$, $R e_{g}$ and $S c$ are interdependent through the temperature of the liquid and gas, which made it difficult to process the data obtained in the one-factor experiment. Therefore, instead of the interdependent criteria, the Peclet criteria $P e_{l}=R e_{l} \cdot \operatorname{Pr}_{l} ; P e_{g}=R e_{g} \cdot \operatorname{Pr}_{g} ; P e_{g}=R e_{\Gamma} \cdot$ Sc were used, respectively, for a liquid film, a gas flow, and diffusion for gas flow.

As a result of such processing of experimental data, the following empirical equations are obtained:

- for laminar mode:

$$
N u_{f}=0,0717 P e_{l}^{-0,58} R e_{g}^{0,43}\left(\frac{t_{w}}{t_{g 0}}\right)^{-0,61},
$$

which is applicable within the variation of dimensionless variables: $562 \leq P e_{l} \leq 2140$; $1992 \leq$ $R e_{g} \leq 782 ; 0,4 \leq t_{w} / t_{g 0} \leq 1,2$, with the standard deviation (standard error) between the calculated and experimental values of the coefficient $\alpha_{f}$ equal to $S=$ $0,0074 \frac{J}{m^{2} \cdot s \cdot d e g}$ (calculated from 13 experiments);

$$
N u_{c}=22,1 \cdot 10^{3} P e_{g}^{-0,73} \operatorname{Re}_{l}^{-0.74}\left(\frac{t_{w}}{t_{l 0}}\right)^{2,02},
$$

applicable at $1362 \leq P e_{g} \leq 3677 ; \quad 127 \leq R e_{l} \leq$ 497; $1,25 \leq t_{w} / t_{l 0} \leq 2,5$ with $S=1,854 \frac{\mathrm{J}}{\mathrm{m}^{2} \cdot \mathrm{s} \cdot \mathrm{deg}}$ for coefficient $\alpha_{c}$ (according to 11 experiments);

$$
S h=1,06 \cdot 10^{-6} P e_{g}^{0,12} \operatorname{Re}_{l}^{-0.51}\left(\frac{t_{w}}{t_{l 0}}\right)^{1,41},
$$

applicable at $1715 \leq P e_{g} \leq 4977 ; 127 \leq R e_{l} \leq 497$; $1,25 \leq t_{w} / t_{l 0} \leq 3,75$ with $S=0,31 \cdot 10^{-7} \frac{\mathrm{kg}}{\mathrm{m}^{2} \cdot \mathrm{s} \cdot P a}$ for coefficient $\alpha_{c}$ (according to 12 experiments);

- for turbulent mode:

$$
N u_{f}=0,378 \cdot 10^{-4} P e_{l}^{0,72} R e_{g}^{0,15}\left(\frac{t_{w}}{t_{g 0}}\right)^{0,06},
$$

applicable at $2140 \leq P e_{l} \leq 3187 ; \quad 1263 \leq R e_{g} \leq$ $7293 ; 0,398 \leq t_{w} / t_{g 0} \leq 1,181$ with $\mathrm{S}=0,0054 \frac{\mathrm{J}}{\mathrm{m}^{2} \cdot \mathrm{s} \cdot \mathrm{deg}}$ for coefficient $\alpha_{f}$ (according to 12 experiments);

$$
N u_{c}=0,213 P e_{g}^{-0,88} R e_{l}^{0.34}\left(\frac{t_{w}}{t_{l 0}}\right)^{1,56},
$$

applicable at $894 \leq P e_{g} \leq 5190 ; \quad 497 \leq R e_{l} \leq 741$; $1,25 \leq t_{w} / t_{l 0} \leq 3,75$ with $S=0,495 \frac{\mathrm{J}}{\mathrm{m}^{2} \cdot \mathrm{s} \cdot \mathrm{deg}}$ for coefficient $\alpha_{c}$ (according to 12 experiments);

$$
S h=0,178 \cdot 10^{-6} P e_{g}^{-0,7} R e_{l}^{0,81}\left(\frac{t_{w}}{t_{l 0}}\right)^{1,63},
$$

applicable at $874 \leq P e_{g} \leq 5046 ; \quad 497 \leq R e_{l} \leq 741$; $1,25 \leq t_{w} / t_{l 0} \leq 3,75$ with $S=0,84 \cdot 10^{-7} \frac{\mathrm{kg}}{\mathrm{m}^{2} \cdot \mathrm{s} \cdot P a}$ for coefficient $\alpha_{c}$ (according to 13 experiments).

The above equations allow us to calculate approximate values of the average heat and mass return coefficients in a falling liquid film that evaporates into a cross-flow of neutral gas.

\section{Conclusions}

An experimental setup has been created, and a methodology has been developed for studying the process of heat and mass transfer in a falling liquid film that evaporates into a cross-flow of a neutral gas, which made it possible to determine the experimental values of the heat and mass return coefficients and establish the following regularities of this process:

1. The liquid film flowing down on a heated surface has a smaller width compared to the width of a film falling down an unheated surface under the same remaining conditions; the difference in the width of such films can reach more than $50 \%$.

2. The dependences of the heat and mass return coefficients on the initial liquid flow rate are extreme in nature with the minimum values of these coefficients at the liquid flow rate, which corresponds to the critical value of the criterion $R e_{l c r} \approx 500$, which indicates a transition from the laminar mode of a film fall to the turbulent one under the considered conditions.

3. The heat and mass transfer to the liquid film in the laminar mode of its falling has, as a rule, a higher intensity than the turbulent one, which is associated with the instability of the film motion in the turbulent mode under conditions of evaporation and cross-flow of gas.

As a result of summarizing the experimental data, empirical equations are obtained for calculating the heat and mass return coefficients in both modes of film falling. 


\section{References}

1. Serafimov, L. A., Frolkova, A. V. (2008). Observance of the first law of Konovalov in the process of rectification with inert gas. Vestnik MITHT, Vol. 3(2), pp. 45-51.

2. Lukashov, V. K., Romanko, S. M., Kostiuchenko, Y. V. (2019). Apparatus for Concentrating a Solution of Sulfuric Acid. Patent of Ukraine, No. 134162.

3. Goncharova, O. H., Rezanova, E. V., Lyulin, Yu. V., Kabov, O. A. (2017). Analysis of a convective fluid flow with a concurrent gas flow with allowance for evaporation. Teplofizika Vysokikh Temperatur, Vol. 55(6), pp. 720-732, doi: $10.7868 / \mathrm{s} 0040364417060072$.

4. Akhmadiev, F.G., Gil'fanov, R.M. (2014). Heat and mass transfer simulation for thin-film two-phase emulsion flow over heated surfaces. Theoretical Foundations of Chemical Engineering, Vol. 49(4), pp. 351-360, doi: 10.7868/S0040357115040028.

5. Aktershev, S. P., Bartashevich, M. V., Chinnov, E. A. (2017). Semianalytic method for heat transfer calculation in the liquid film under conditions of a constant heat flux on the wall. Teplofizika Vysokikh Temperatur, Vol. 55(1), pp. 115-121, doi: $10.7868 / \mathrm{S} 004036441701001 \mathrm{X}$

6. Kabov, O. A., Kabova, Y. O., Kuznetsov, V. V. (2012). Evaporation of a non-isothermal liquid film in a microchannel with a satellite gas flow. Doklady Akademii Nauk, Vol. 446(5), pp. 522-526.

7. Pecherkin, N. I, Pavlenko, A. N., Volodin, O. A. (2011). Heat transfer during the evaporation of falling films of a mixture of freons on a smooth and structured surface. Thermophysics and Aeromechanics, Vol 18(4), pp. 605-616.

8. Dubrovskyi, V. V., Pidvysotskyi, O. M., Shraiber, O. A. (2009). An experimental investigation of the heat transfer of a liquid film flowing over a profiled surface with air. The Problems of General Energy, Vol. 19, pp. 39-45.

9. Shraiber, A. A., Dubrovskyi, V. V., Podvysotskyi, A. M. (2010). Generalization of experimental data on the heat transfer of a liquid film, flowing over plane and profiled surfaces, with air. Industrial Heat Engineering, Vol. 32(4), pp. 21-27.

10. Pismennyy, Ye. N., Tuz, V. Ye., Lebed, N. L. (2009). Heat and mass transfer in channels with a mesh coating of a liquid film during countercurrent gas movement. Eastern-European Journal of Enterprise Technologies, Vol. 4/6(40), pp. $63-68$.

11. Statsenko, V., Statsenko, L., Bernavskaya, M. (2018). Modelling of heat transfer processes in film liquid devices when obtaining fresh water. School of Engineering Bulletin, Vol. 3(36), pp. 94-103, doi.org/ 10.5281/zenodo.1408235.

12. Churakova, S. K. (2014). Development of Energy-Saving Technologies for Oil and Gas Processing Based on Cross-Flow Nozzle Contact Devices. Ufa State Petroleum Technical University.

13. Chinnov, E. A. (2013). Thermocapillary effects in nonisothermal liquid film at high Reynolds numbers. Teplofizika Vysokikh Temperatur, Vol. 51(2), pp. 294-300.

14. Kuznetsov, V. V., Vitovskii, O. V., Krasovskii, V. A. (2007). An experimental investigation of modes of flow under conditions of evaporation of liquid on a vertical heating surface. Teplofizika Vysokikh Temperatur, Vol. 45(1), pp. 77-84.

15. Lukashov, V. K., Kostiuchenko, Y. V., Timofeev, S. V. (2019) Hydrodynamics of a liquid film downflow on a flat surface in evaporation conditions into a flow of neutral gas. Journal of Engineering Sciences, Vol. 6(1), pp. F19-F24, doi: 10.21272/jes.2019.6(1).f4.

16. Vorontsov, E. G., Tananaiko, Yu. M., (1972). Heat Transfer in Liquid Films. Tekhnika. Kyiv, Ukraine.

17. Actershev, S. P. (2016). Stability, Nonlinear Waves and Transport Processes in Liquid Films under Difficult Conditions. Kutateladze Institutr of Thermophysics, Siberian Branch of the RAS. 